\title{
Tipologia de Redes Sociais Brasileiras no Fotolog.com ${ }^{1}$
}

\author{
Raquel Recuero ${ }^{2}$ \\ UCPel/UNISINOS
}

\begin{abstract}
Resumo: $O$ presente trabalho apresenta uma tipologia para redes sociais $e$ tipos de fotologs brasileiros encontrados no Fotolog.com. Trata-se de um estudo de caso cujo objetivo é observar como a apropriação do sistema transforma um site de publicação de fotografias em um site de redes sociais $e$ as formas de uso social que daí decorrem. Como formas básicas de apropriação temos a construção de identidade e a interação social. Através delas, é possível observar que os fotologs são utilizados como elementos centrados ou na identidade ou na interação e que tipo de rede emerge do estudo desses fotologs através dos comentários observados.
\end{abstract}

Palavras-chave: redes sociais; interação social; fotolog.

VAbstract: The following work presents a typology for social networks found in Fotolog.com. It deals with brazilian fotologs and how fotolog, as a tool to publish photographies and comment them can create new social uses. Basic forms of usage, such as identity construction and social interaction were observed and based on them fotologs and their networks were classified in identity -centered and interaction-centered.

Key words: social networks; social interaction; fotolog.

\footnotetext{
${ }^{1}$ Trabalho submetido ao NP de Tecnologias da Informação e Comunicação, VII Encontro dos Núcleos de Pesquisa da Intercom 2007, a ser realizada em Santos/SP.

${ }^{2}$ Doutora em Comunicação e Informação (UFRGS/2006), pesquisadora e professora da ECOS/UCPel e da Comunicação Digital (UNISINOS).
} 


\section{Introdução}

As redes sociais são normalmente associadas a um grupo de atores (nós) e suas conexões (arestas) (DEGENNE e FORSÉ, 1999; SCOTT, 2000; WASSERMAN e FAUST, 1994). No ciberespaço, essas redes são complexificadas pela apropriação de um novo espaço, o espaço virtual (EFIMOVA, 2005, boyd \& HERR, 2006; boyd, 2006 e 2004), através da interação mediada pelo computador (PRIMO, 2003). Essa apropriação é capaz de gerar novos usos, novas formas de construção de espaços sociais. Este trabalho, procura assim compreender como essa apropriação, realizada através da interação, reflete-se nas redes sociais na Internet e como esses usos são percebidos pelos agentes envolvidos.

Baseado em parte da tese de doutorado da autora, o foco que é apresentado aqui constitui-se em duas premissas fundamentais: A observação da apropriação de um sistema de publicação de fotografias na Internet (Fotolog) por seus usuários (fotologueiros) e a verificação de como esta apropriação reflete-se na rede social constituída através do sistema. Através desta análise, realizada durante um período de quase três anos de coleta, observação e análise de dados, discutir-se-á os usos da ferramenta e seu impacto social, focando-se em uma abordagem de análise de redes sociais e apresentando uma tipologia de redes encontradas no sistema.

Como estudo de caso e objeto, foi escolhido o Fotolog.com pela sua simplicidade e pelo expressivo número de brasileiros ${ }^{3}$ que o utilizam, bem como pela escassez de trabalhos com foco no sistema no Brasil.

O Fotolog.com4 é um serviço de publicação de fotografias na Internet que permite a seus usuários receber comentários para cada foto e acrescentar amigos. Assim, as redes sociais são observadas a partir das páginas pessoais de publicação de fotografias (fotologs) como os nós e as interações entre os diversos indivíduos representados por seus fotologs ${ }^{5}$ como as conexões. Cada fotolog possui uma

\footnotetext{
3 Em 2004 foi feita a escolha, quando o Brasil tinha mais de 200 mil fotologs, sendo o país com maior número de fotologs cadastrados no sistema. No início de 2006, o Fotolog.com retirou as estatísticas do ar.

$4 \mathrm{http}: / /$ www.fotolog.com

5 A percepção das páginas pessoais como representações dos indivíduos no ciberespaço já foi construída e exaustivamente discutida por autores como Donath (1999), boyd (2004) e Döring (2002). Por conta disso, não será retomada neste trabalho.
} 
estrutura bastante simples. No centro das páginas fica a fotografia publicada, seguida de um texto também publicado pelo fotologueiro. De cada um dos lados ficam pequenas fotografias, uma lista dos "amigos/favoritos" à direita e uma lista das fotografias anteriormente publicadas à esquerda. Abaixo, a lista dos comentários recebidos e o espaço para comentar (Figura 1).

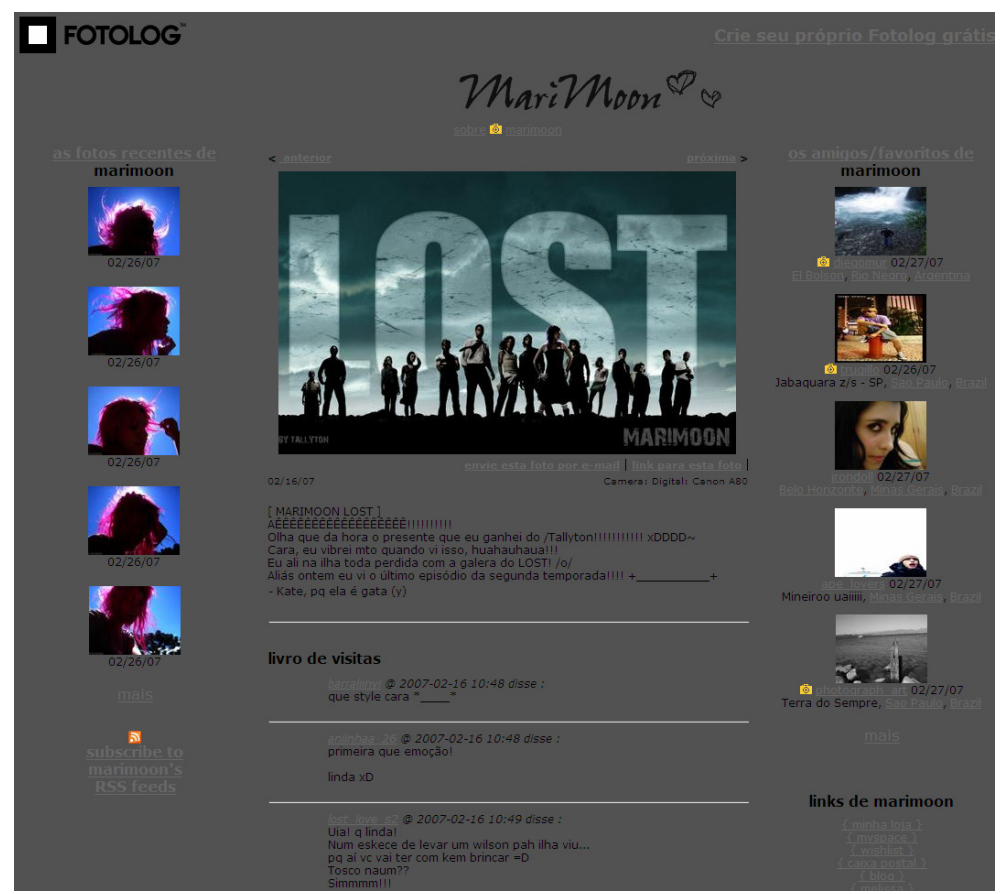

Figura 1: Exemplo de fotolog

Os fotologs podem ser comuns ou gold camera. Os comuns podem publicar apenas uma fotografia por dia e receber 20 comentários (na época do estudo, eram apenas 10). Aqueles que se enquadram na categoria gold camera podem publicar até seis fotos por dia e receber até 200 comentários (na época do estudo, apenas 100) ${ }^{6}$.

Embora tenha sido criado com o propósito de mostrar fotografias, o Fotolog foi, no entanto, apropriado no Brasil de maneiras diferentes, focadas, principalmente, na sociabilidade.

\footnotetext{
${ }^{6}$ Como este trabalho refere-se ao período de coleta de dados anterior ao aumento do número de comentários, é preciso que se considere que, na época, eram apenas 10 e 100 comentários, respectivamente analisados por fotolog.
} 


\section{Metodologia}

Para observar as características dos fotologs brasileiros na Internet a partir da interação em suas redes sociais, foi construído um método que utilizou, ao mesmo tempo, perspectivas qualitativas e quantitativas em estágios alternados.

Em um primeiro estágio, qualitativo, foram observados 20 fotologs, escolhidos de forma arbitrária, pois era necessário que fossem fotologs de usuários brasileiros. Assim, diversos fotologs foram observados até que se obtivesse uma quantidade de brasileiros. A partir de cada um desses fotologs foi realizada uma abordagem ego (WASSERMAN e FAUST, 1994, DEGENNE e FORSÉ, 1999 e SCOTT, 2000), e foram observados os comentários que eram realizados no período de dois meses. Os comentários foram escolhidos pois caracterizam-se no principal meio de interação entre os fotologueiros. Além disso, cada usuário possui um apelido (nickname) único no sistema, que o identifica através de senha. Esse apelido é também a URL do fotolog do usuário. A cada comentário, os usuários precisam identificar-se para que os demais possam perceberem com quem estão interagindo. Esta identificação é feita através deste apelido único. Cada um dos 20 fotologs inicialmente escolhidos teve seus comentários observados e coletados. Através da identificação, foram criadas matrizes entre todos os comentaristas dos fotologs, criando assim, as primeiras redes. Nesta fase, foram observados 154 fotologs em dois $\operatorname{anos}^{7}$.

Além da coleta dos comentários, as interações também foram observadas diariamente, bem como as trocas contidas nelas. Finalmente, foram entrevistados 56 usuários a respeito do uso do fotolog, que adicionaram percepções individuais à pesquisa. Com base nos dados obtidos neste estágio a respeito das formas de apropriação, elaborou-se uma tipologia de fotologs. A partir desta tipologia, foi criada a hipótese de que os fotologs com apropriações diferenciadas seriam também capazes de gerar redes sociais diferenciadas. Assim, os fotologs brasileiros pareciam ser focados em (1) interagir com outros usuários através dos comentários; (2) construir identidade pessoal. Cada uma dessas apropriações seria capaz de gerar uma rede que

\footnotetext{
7 Esta abordagem é relativamente nova no sentido de que, embora Mishne e Glance (2006), Lento et. Al (2006) e Liu, H., Maes, P. and Davenport, G (2006) tenham analisado as redes sociais através das trocas de comentários, essa análise não tinha ainda sido realizada em conjunto com uma observação qualitativa das trocas sociais no espaço.
} 
teria propriedades e estrutura também diferentes, como forma de suprir as necessidades de seus usuários.

Com base nessa hipótese, iniciou-se uma segunda etapa de coleta de dados, a partir do uso de um crawler $^{8}$. O crawler percorreu a rede a partir de determinados fotolog-egos, percebidos como exemplos de cada tipo de apropriação observada e recolhendo comentarios. O objetivo do uso do cralwer foi recolher dados a respeito de cada tipo de rede observada de forma a ampliar a compreensão de sua estrutura baseada nos comentários trocados entre usuários. Por conta disso, foram escolhidos 18 fotologs ego com características específicas de cada tipo, nos quais o crawler foi aplicado. Como resultado, o crawler percorreu e recolheu dados de mais de 5 mil fotologs associados a cada rede.

Juntamente com os dados quantitativos obtidos neste estágio, foram também analisadas de forma qualitativa essas redes e observadas as interações no sentido de compreender se os dados quantitativamente obtidos poderiam ser relacionados aos qualitativos. Os dados obtidos nessas duas etapas auxiliaram a compreender como os fotologs são apropriados pelos agentes e como seus diferentes usos geram diferentes redes sociais, conforme apresentaremos a seguir.

\section{Redes Sociais nos Fotologs}

Embora constituído de um sistema bastante simples, os fotologs escondem uma complexidade grande em suas formas de apropriação. Embora o sistema possa ser utilizado para o armazenamento de fotografias, ele é mais utilizado (1) como forma de construir uma identidade individual que possa ser reconhecida pelos demais e (2) como espaço de interação, onde é possível perceber a estrutura das redes sociais.

Por causa das limitações do sistema, o Fotolog não proporciona aos usuários quase nenhuma forma de personalização. Entretanto, autores como Döring (2002) e Donath (1999) demonstraram que a personalização é uma condição necessária para a interação mediada por computador. Assim, a apropriação das ferramentas de CMC é constantemente perpassada pela construção de si, tornando o ciberespaço

\footnotetext{
${ }^{8}$ Crawler é um software que coleta dados a partir de parâmetros previamente estipulados. 
reconhecível como um espaço individual. É o caso dos fotologs que, dentro das possibilidades do sistema, são constantemente reconstruídos para apresentar as últimas "atualizações do self” (DÖRING, 2002).

Cada fotologueiro é identificado através de um apelido único, que é o mesmo utilizado em seu endereço no fotolog (www.fotolog.com/apelido). O apelido é condição para a interação registrada, pois apenas um usuário identificado pode comentar com o seu apelido. Mesmo quando os usuários estão offline, costumam digitar o apelido pelo qual são conhecidos, tornando-o a forma mais simples de identificação no sistema. Donath (1999) já comentava a importância do apelido como elemento de reconhecimento individual na Internet, elemento que foi igualmente verificado em outros sistemas por outros autores (RECUERO, 2002; boyd, 2004; boyd \& HERR, 2006). O apelido, no entanto, não é a única forma de identificação. O Fotolog ainda apresenta a mudança de cor de fundo e de cor das letras, além de criação de um título para cada página e uso de imagem no titulo para usuários gold. Essas não são, no entanto, as únicas formas de construir identidade. Os usuários possuem duas apropriações-chave no sentido de construção do eu: o uso de postagens (fotos e textos) e o uso dos amigos/favoritos.

As imagens publicadas são essenciais para a construção da identidade. Por conta disso, é muito freqüente a publicação de imagens de si (ego shots). Cada fotografia pode, assim, permitir aos leitores perceber um dos aspectos da personalidade do fotologueiro. Assim, uma foto com o cachorro, com os amigos ou mesmo com o $\mathrm{CD}$ favorito dizem muito sobre cada usuário. As imagens são constantemente acompanhadas em sua postagem por um texto. $\mathrm{O}$ texto também refere-se a uma construção de si, com letras de músicas, informações pessoais e mesmo elementos do dia a dia (de forma similar à observada por Carvalho, $2003 \mathrm{e}$ Sibilia, 2003 e 2004 nos weblogs).

A segunda forma de apropriação é o uso dos demais fotologs como elementos de identificação. Os usuários entrevistados relataram a apropriação de outros fotologs como forma de construir seus gostos pessoais, hobbies e mesmo ideologias, de forma semelhante à realizada nas comunidades do Orkut 9 . Deste modo,

9 Vide, por exemplo, Fragoso (2006) e Recuero (2005). 
a lista de "amigos/favoritos" é um elemento compreendido como forma de dizer quem se é.

Essa construção é fundamental para que os usuários percebam cada fotolog como uma representação de alguém com quem se pode interagir. Essa construção gera identificação e a percepção do fotolog como um espaço pessoal. Essa personalização é tão forte que muitos usuários utilizam os comentários para ofender e perseguir o fotologueiro, percebendo o espaço como um modo de atingir pessoalmente o usuário. É um fato comum observado junto aos entrevistados, muitos deles (36) vitimas, outros (20), através de amigos e conhecidos.

Essas duas formas de apropriação são chaves para que o Fotolog passe de um site ou sistema de publicação de fotografias para um site de redes sociais (sistema que sustenta o uso das redes sociais na Internet, de acordo com boyd, 2006). São essas formas de apropriação que permitem que laços sociais emerjam dos grupos que utilizam o fotolog como espaço de socialização.

O estudo dos sites de redes sociais na Internet tem sido ampliado e tem recebido cada vez mais atenção da comunidade científica ${ }^{10}$. Redes sociais são geralmente compreendidas como compostas de atores (nós) e seus laços e capitais sociais (conexões). No caso dos fotologs, observaremos cada ator como sendo representado por seu fotolog e as interações, como apresentadas através dos comentários. Os fotologs aqui são percebidos como espaços de interação, onde diversos usuários encontram-se para interagir. Além disso, cada fotolog também representa um usuário único, já que seu link só pode ser utilizado nos comentários quando o usuário está utilizando sua própria conta. Deste modo, consideraremos que as interações sociais entre os fotologueiros são capazes de gerar relações sociais e laços sociais.

Os usuários utilizam o fotolog para trocar informações mas, mais do que isso, para construir, publicizar ou mesmo, romper laços sociais. Esses laços são construídos através das trocas sociais que acontecem nos comentários dos fotologs. Além dos laços sociais, é possível também identificar capital social nesses fotologs. O capital social é relativo aos valores que emerge das relações sociais forjadas nas redes

${ }^{10}$ Vide boyd, 2004 e 2006; Liu, Maes \& Davenport, 2006; Lento, et al., 2006; McDonald, 2006, boyd \& Herr, 2006; Stutzman, 2006, entre outros 
(GYARMATI e KYTE, 2004; COLEMAN, 1988). Esses valores auxiliam a determinar também a qualidade de um determinado laço entre dois indivíduos (RECUERO, 2006), pois aponta para o conteúdo das relações sociais na rede (GYARMATI e KYTE, 2004). Bertolini e Bravo (2004) apontam que o capital social deve ser compreendido como uma perspectiva de recursos dos quais dispõe um grupo de indivíduos, representados por aspectos específicos da estrutura social que os auxiliam a atingir objetivos e interesses (na esteira dos estudos de Coleman, 1988). Para os autores, o capital social pode ter tipos relacionados também ao tipo de laço social que constitui a rede. $\mathrm{O}$ capital social de primeiro nível está relacionado às relações que cada rede possui (capital relacional), às suas normas (capital normativo) e às informações que circulam nela (capital cognitivo). Já o capital social de segundo nível é aquele que caracteriza relações mais institucionalizadas (e, portanto, relacionadas a um conjunto de laços mais fortes), com maior envolvimento dos indivíduos, relativo ao capital institucional e ao capital de confiança no ambiente social. A identificação dos tipos de capital social associados a cada grupo, através de suas interações recíprocas, é elemento fundamental para mostrar que tipo de laço está presente na rede (RECUERO, 2006).

Esses laços podem ser percebidos como laços fortes ou fracos, utilizando a definição de Granovetter (1973). Os laços fortes são aqueles constituídos por grande variedade de capital social de primeiro e segundo nível (BERTOLINI E BRAVO, 2004). São laços caracterizados por relações de intimidade, de trocas informativas e afetivas, de amizade. São laços percebidos pelos próprios usuários como fortes, caracterizados por um grande numero de interações recíprocas. Já os laços fracos são aqueles constituídos pelas trocas sociais esparsas, com menos intimidade, caracterizada por pouca afetividade e pouco capital social envolvido. São laços percebidos pelos usuários como fracos, relacionados a "conhecidos" mais do que a pessoas mais próximas. Os laços fracos possuem menos variedade e quantidade de capital social, associada a sua menor institucionalização e confiança (QUAN HAASE \& WELLMAN, 2002).

Os laços e o capital social são elementos fundamentais para a compreensão dos tipos de fotologs e das redes que são associadas a eles. São dois elementos básicos 
para que possamos compreender os tipos de redes associados a cada grupo de fotolog.

\section{Tipos de Fotologs nas Redes Sociais}

A partir da observação, os fotologs inicialmente observados foram classificados em duas formas: fotologs centrados na identidade e fotologs centrados na interação. Esses dois tipos de fotologs compreendem, inicialmente a totalidade dos grupo de fotologs observados na primeira etapa da pesquisa.

\subsection{Fotologs Centrados na Interação}

O primeiro tipo de fotolog observado foi aquele centrado na interação social. Dentre os fotologs inicialmente observados, fotologs com essas características foram a expressiva maioria ( 15 dentre os 20). Chamamo-los assim porque se constituem em fotologs cujo valor principal reside em sua apropriação como forma de concentrar a interação social. Esses fotologs são aqueles cujos usuários tratam suas publicações como uma forma de concentrar principalmente capital social relacional. Esses fotologs parecem ser bastante focados no ego, já que em todos os fotologs observados há pelo menos uma foto do fotologueiro. Na maioria deles, há um grande centro no indivíduo, seja ele constituído através das fotografias, seja ele constituído através dos textos pessoais que acompanham os fotologs. Essa construção "pessoalizada" é essencial para que esse tipo de interação surja.

É justamente a partir da percepção do fotolog como um elemento que representa um indivíduo é que existe a possibilidade de que os laços sociais emerjam. Como resultado, as interações presentes nesse tipo de fotolog possuem características essencialmente diferentes. Em primeiro lugar essas interações são mais recíprocas, no sentido de que há um grupo de usuários que constantemente interage através do mesmo conjunto de fotologs ${ }^{11}$, como se todos os fotologs do grupo constituíssem um terreno de interações mútuas entre seus donos. Essa interação é mútua no sentido definido por Primo (2003) de interação construída através das trocas sociais. Ela constitui um tipo específico de laço social, o laço relacional que é o laço que emerge

\footnotetext{
${ }^{11}$ De forma semelhante aos webrings de weblogs (vide RECUERO, 2003).
} 
da interação entre os indivíduos e que, frequentemente, pode gerar laços mais fortes, com maior quantidade de capital social.

O laço social emergente, constituído através da interação mútua mediada por esses fotologs necessita de constante investimento para que sobreviva no ciberespaço. É um laço que está associado unicamente à interação. Quando esta não ocorre por um largo período de tempo, o laço tende a enfraquecer. Logo, para manter o laço e o capital social decorrente do mesmo, é preciso constante investimento de tempo em comentar os fotologs dos comentaristas e publicar novas fotos para que se receba novos comentários. Deste modo, as redes que surgem através desses fotologs tendem a ser diferenciadas.

\subsubsection{Redes Sociais Centradas na Interação}

Redes sociais centradas na Interação são redes cujas conexões entre os nós emergem através das trocas sociais realizadas pela interação mútua. Essas são redes normalmente pequenas, pois a quantidade de comentários recíprocos, custosos e que demandam investimento - pois realmente representam trocas sociais - é concentrada em poucos nós, tanto pelo custo de investimento, quanto pelo tempo necessário para que as trocas sociais aconteçam.

Essas redes, quando analizadas através da quantidade de comentários recíprocos, mostram clusters altamente conectados, formando grupos com grande quantidade de laços sociais entre os nós (Figura 2).

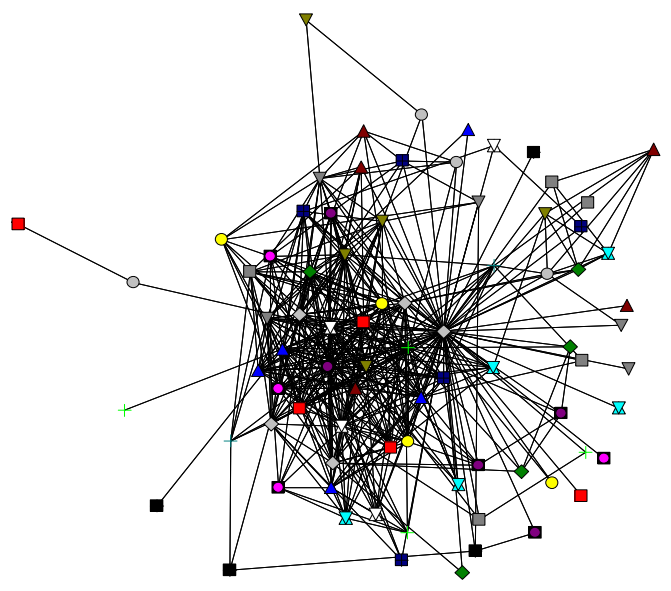

(a)

Figura 2: Redes encontradas em torno de fotologs centrados na interação. A distâcncia entre os nós é inversamente proporcional ao número de comentários trocados entre eles.

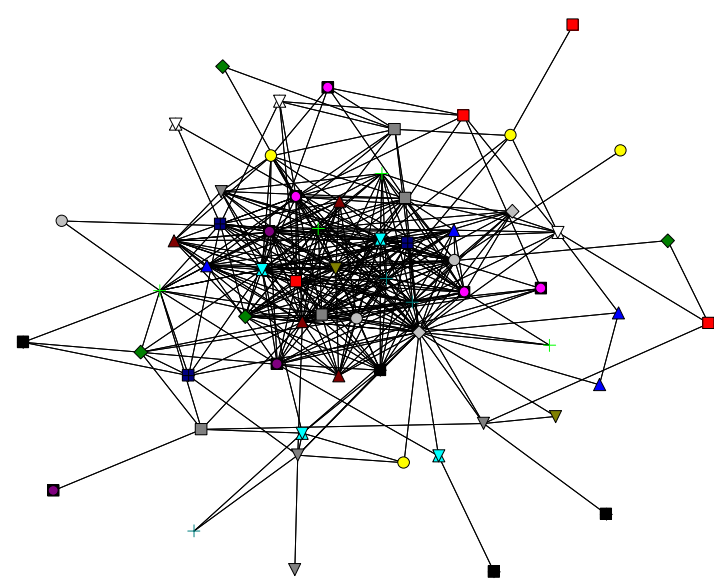

(b) 
Na figura, vemos dois exemplos das redes observadas em torno dos fotologs centrados na interação. Observa-se que há uma grande quantidade de nós e de tríades (usuários que comentam entre si), o que seria um indicativo de sociabilidade importante.

São redes que também parecem indicar possuir uma forte conexão geográfica, pois a maioria dos nós próximos ao núcleo está localizado em uma mesma cidade (Figura 3).

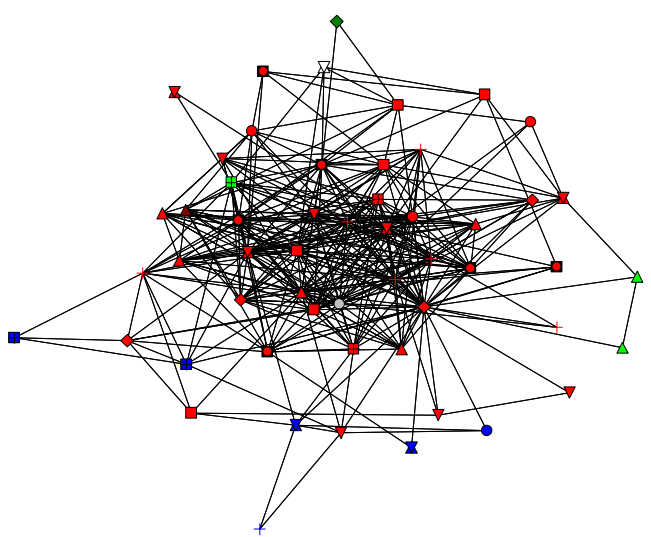

Figura 3: Exemplo de rede formada em torno de fotolog centrado na interação. Nós com a mesma cor estão na mesma cidade.

\subsection{Fotologs centrados na Identidade}

Um segundo tipo de fotolog observado foi aquele centrado na identidade. Foram observados 5 desses fotologs no grupo inicial. Esses fotologs são essencialmente diferentes, na medida em que são fotologs temáticos. Alguns desses fotologs permitem que outros fotologueiros enviem suas fotos para o mesmo, desde que estejam dentro da temática proposta. São, assim, fotologs coletivos. Outros fotologs temáticos são individuais, mas fotologueiro publica sempre imagens com uma mesma temática, seja uma cor, um ator famoso ou mesmo um sentimento. A principal característica observada nesses fotologs é proveniente das motivações dos usuários para com suas conexões para esses fotologs: São utilizados como elementos de construção de identidade, ou seja, as pessoas os adicionam/comentam ou publicam suas fotos neles porque sua associação com esse fotolog é percebida como uma forma de mostrar gostos e interesses pessoais. 
Os usuários entrevistados identificam esses fotologs como espaços não de interação, mas simplesmente de construção de identidade. Aqueles que publicaram suas fotos nesse tipo de fotolog colocam-nas como um link em seu próprio fotolog, para mostrar aos demais. Além disso, os usuários percebem esses fotologs como elementos utilizados pelos outros também com a mesma função de construção de identidade, de composição de um perfil.

Dentre os fotologs observados aqueles com características de identidade, possuem uma grande quantidade de comentaristas diferentes. Nos dados obtidos pelos crawlers, esses fotologs possuem uma media de 1,9 comentários por comentarista e apenas um a cada 344,5 comentários é respondido. Não foi observada uma grande quantidade de comentários em cada foto, e menos ainda, uma grande quantidade de comentários provenientes dos mesmos usuários.

Com isso, observamos que esses fotologs são vistos e construídos pelos demais usuários como fotologs centrados na identificação. Seus laços sociais são fracos, quando existentes, pois a falta de comentarios é freqüente, mesmo nas interações que possuem reciprocidade (GRANOVETTER, 1973, WELLMAN, 1997). O capital social observado está relacionado com valores relacionados ao estar conectado ao grupo como forma de identificação (capital relacional, nos termos de Bertolini e Bravo, 2004). Outro valor é a visibilidade social, que também é decorrente da associação para com esses fotologs, uma vez que aumenta as chances de ser visto por outros usuários. A agregação em torno desses fotologs é uma forma de personalização, auxiliando aos demais fotologs centrados na interação que sua associação a fotologs centrados na identidade auxilie na construção de um perfil único. Essa construção pode auxiliar a gerar identificação com outros usuários, de forma a proporcionar interações sociais (DONATH, 1999; EFIMOVA, 2005).

\subsubsection{Redes em Fotologs Centrados na Identidade}

Talvez pelas suas diferenças essenciais na apropriação, os fotologs centrados na identidade possuem uma rede associada bastante diferente daquela observada nos fotologs centrados na interação. Esses fotolog possuem uma grande quantidade de comentários, mas uma igual quantidade de comentaristas. Assim, sua rede, ao contrario daquela formada nos fotologs centrados na interação é muito maior. Se 
considerássemos apenas os links unilaterais, esses fotologs certamente poderiam ser percebidos como conectores (BARABÁSI, 2003), uma vez que seu in-degree ${ }^{12}$ seria muito alto. Seu out-degree, no entanto, é baixo, pois não há reciprocidade para a maior parte dos comentarios. Se observarmos, assim, apenas as conexões recíprocas, a rede que veremos é pouco conectada, com muitas ilhas dentre suas conexões. Alguns desses fotologs, inclusive, mostram-se bastante desconectados. Alem disso, há uma redução expressiva da quantidade de nós mostrados na rede quando reduzida apenas aos comentaristas recíprocos (Figura 4).

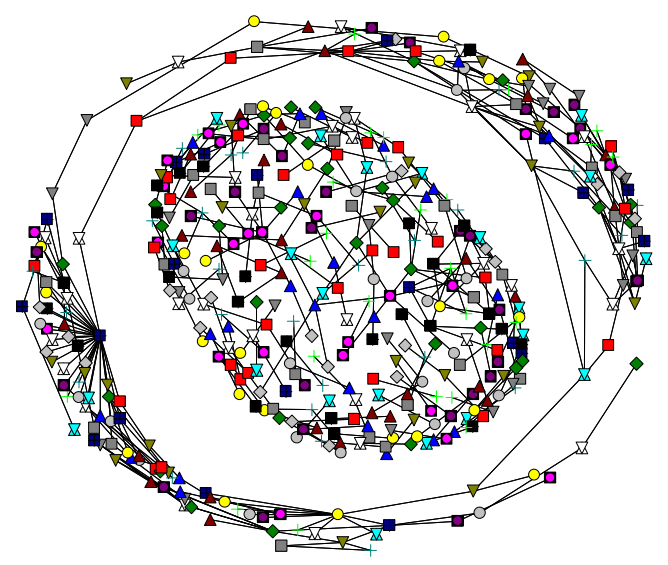

(a)

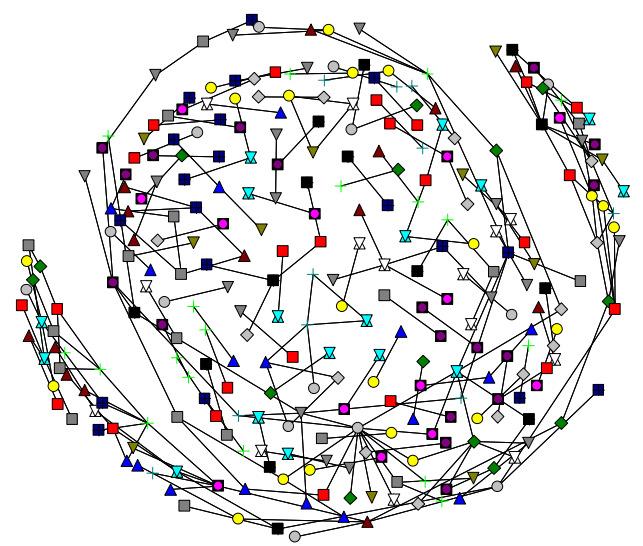

(b)

Figura 4: Redes observadas a partir de fotologs centrados na identidade.

Nas figuras, observa-se que a estrutura de tais redes é bastante diferente das redes centradas na interação. Essas redes mostram-se como compostas de diversas redes menores, não relacionadas entre si (possivelmente redes baseadas em interação). Também se vê que essas redes não estão relacionadas entre si, a não ser pelo fotolog ego. O que se observa e que aparece nas redes relacionadas ao fotolog centrado na identificação é justamente o fato de que as interações não estão concentradas nesses fotologs, mas nas redes conectadas a ele. Isso talvez fortaleça a hipótese levantada neste trabalho de que os fotologs centrados na identidade são elementos para a conexão entre as redes centradas na interação. Isso mostraria também o papel importante desses fotologs como conectores no sentido de reduzir a

\footnotetext{
$12 \mathrm{O}$ in-degree é compreendido como a quantidade de conexões de entrada em um nó. O outdegree é a quantidade de conexões de saída do mesmo nó.
} 
distancia entre as diversas redes formadas pelos fotologs centrados na interação (WATTS e STROGATZ, 1998, WATTS, 2003).

Não foram encontradas correlações geográficas entre os fotologs centrados na identidade. Diferentemente dos fotologs centrados na interação, o principal ponto de agregação parece ser o interesse comum.

\subsection{Fotologs Híbridos}

Um terceiro caso encontrado foram fotologs individuais, egocêntricos, focados na interação, mas com características de fotologs centrados na identidade. Ou seja, ao mesmo tempo em que esses fotologs são centrados nas interações, também são usados como construtores de identidade. Chamaremos esses fotologs de híbridos, pois possuem características de ambos os grupos.

Esses fotologs costumam ser aqueles que possuem um grande crescimento dentro do sistema, com uma grande quantidade de interagentes e uma grande quantidade de amigos e favoritos. Também são associados às “celebridades”, ou seja, usuários que se tornaram muito famosos dentro do sistema.

Nesses casos, foi possível observar que esses fotologs possuem uma rede de comentaristas freqüentes, os quais também recebem comentários. No entanto, juntamente com esses, há uma expressiva quantidade de "fãs", outros usuários que procuram associar-se com eles, a fim de utilizar esse capital social como forma de construir identidade. Ser amigo de uma celebridade, para muitos, é uma forma de "emprestar" parte da fama e mostrar que "se é alguém" dentro do sistema (RECUERO, 2005). Outro elemento importante é a visibilidade adquirida ao ser associado a um desses fotologs. Como são muito populares, há muitas visitar e aparecer na lista de amigos/favoritos é uma maneira de ganhar visibilidade junto ao grupo. Essa mesma visibilidade pode ser igualmente obtida a partir dos comentários.

Assim, esses fotologs possuem uma dupla faceta: De um lado possuem uma grande quantidade de comentaristas esporádicos, com características de apropriação de identidade e, de outro, com alguns comentaristas freqüentes, com característica de fotologs centrados na interação. Do ponto de vista quantitativo, há uma media de apenas 2,3 comentários realizados por apelido(o que é uma média baixa, mas 
facilmente explicada pela quantidade de comentaristas esporádicos em relação aos comentaristas freqüentes) e apenas 1 a cada 9,8 comentários é respondido. Esse dado mostra também que há um esforço dos fotologueiros "celebridades" no sentido de manter sua fama na rede. Muitos comentam também esporadicamente os "fãs", com mensagens de agradecimento e elogios, mostrando seu apreço pelo carinho recebido.

Esses fotologs também costumam ser egocêntricos - com muitas fotos do dono do fotolog, todas cuidadosamente produzidas e com regularidade em suas postagens. Alem disso, o capital social decorrente da quantidade de "fãs" é rapidamente percebido pelos usuários, que passam a investir tempo e esforço na manutenção da rede, com comentários esporádicos nos fãs - como explicado - e investimento na troca de links com outros fotologs. Deste modo, há um ganho de visibilidade também para o dono do fotolog ${ }^{13}$.

\subsubsection{Redes Híbridas}

A rede que é proveniente dos fotologs híbridos também apresenta características híbridas. Inicialmente, essas são redes maiores do que as redes centradas na interação. Há um número bem maior de nós, embora as conexões não cresçam na mesma proporção. Além disso, há um número pequeno de tríades, em relação às redes focadas na interação, alem de menos quantidade de capital social relacionado à intimidade e à reciprocidade.

Nesses fotologs, observa-se principalmente capital social da categoria relacional (BERTOLINI e BRAVO, 2004), associado à visibilidade social, diretamente relacionado ao capital social de primeiro nível. No entanto, outras formas de capital social, como o capital normativo e cognitivo também podem aparecer. Dentro dos comentaristas freqüentes, há capital social relacional, associado ao pertencer ao grupo, obter suporte social, apoio, e conhecer pessoas; capital social cognitivo, no sentido de trocar informações e conhecimento; capital social normativo, a partir do reconhecer as normas de reciprocidade que envolvem as trocas sociais. Esse capital social pode ser ainda institucionalizado, como parte do segundo nível de capital social. Deste modo, observa-se o primeiro nível de capital social relacionado à

${ }^{13}$ Fotologueiros famosos já foram, inclusive, contratados por agencias de propagandas para trabalhar em campanhas, como é o caso de /marimoon, /ape, /impar, contratadas para trabalhar na campanha do calçado Melissa. 
visibilidade em relação à parte da rede que tem semelhança com a rede centrada na identidade e uma maior pluralidade de capital na rede que tem semelhança com a rede centrada na interação.

Esses fotologs também tendem a centralizar interações, funcionando como conectores nas redes (BARABÁSI, 2003). Suas redes podem ser muito grandes, como as redes centradas na identificação, mas ainda assim, apresentar uma pequena estrutura semelhante à apresentada pelas estruturas centradas na interação. Apesar disso, essas estruturas são consideravelmente mais fracas do que aquelas encontradas nas redes centradas na interação, o que é bastante compreensível, uma vez que há uma certa competição pelo espaço nos comentários, tanto entre as conexões fracas quanto entre as fortes.

$\mathrm{Na}$ Figura 5 temos um exemplo dessas redes. Observa-se que a rede de comentários recíprocos é pequena, apresentando uma similaridade com as redes centradas na interação. Apesar disso, a rede original, incluindo as conexões unilaterais no tempo observado, é muito maior, chegando a centenas de conexões.

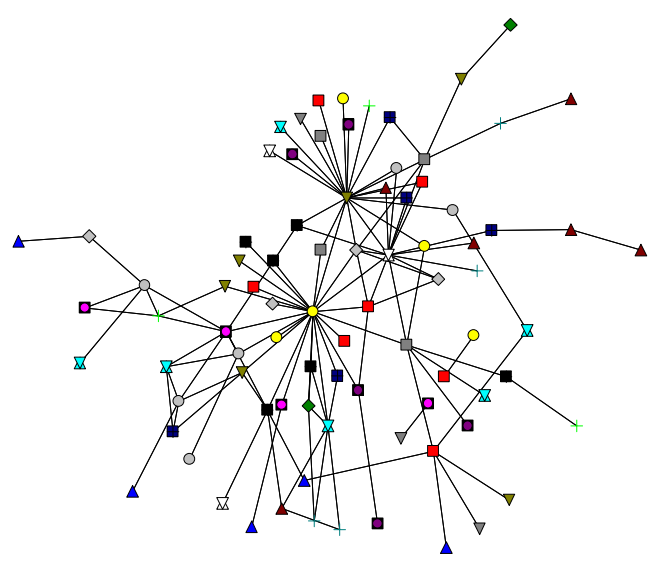

Figura 5: Exemplo de rede observada entre os fotologs híbridos.

Nessas redes também não foi encontrada uma relação direta com a proximidade geográfica. De modo semelhante às redes focadas na identidade, esses fotologs parecem ser focados mais em um interesse comum do que na proximidade geográfica. Além disso, as redes híbridas poderiam, também, constituir-se em intermediárias entre as redes centradas na identidade e na interação, podendo ser percebidas como um "estágio" entre os dois extremos. No entanto, mais estudos 
precisam ser desenvolvidos neste sentido, já que o tempo observado não foi suficiente para definir este tipo como um estágio apenas.

\section{Apontamentos Finais}

Neste trabalho, apresentam-se os resultados de parte da tese de doutorado da autora. A partir de um estudo de caso da apropriação da ferramenta do Fotolog no Brasil, procurou-se desenvolver como essa apropriação é capaz de gerar redes sociais e que tipo de redes sociais pode verificar-se a partir dela. Em cima dos elementos observados em um estudo qualitativo e quantitativo. Mostrou-se que os usuários do sistema utilizam-no de forma a faze-lo um site de redes sociais, mais do que um espaço de armazenagem de fotografias. Assim, há fotologs de três tipos: centrados na identidade, na interação e um tipo híbrido. Em cima de cada tipo, procurou-se semelhanças e diferenças, além da estrutura e composição das redes.

Traz-se aqui uma proposição e uma discussão a respeito das formas através das quais as pessoas no Brasil podem utilizar ferramentas e transformá-las em espaços de interação. Muito ainda resta a ser estudado e melhor compreendido a respeito do fenômeno. Este trabalho retrata apenas um estudo de caso (apesar da abordagem quantitativa, centrada em redes ego, ainda é apenas exemplificativo) e, por conta disso, traz uma abordagem mais profunda e menos ampla. Ainda assim, traz uma contribuição no sentido de auxiliar a pensar a apropriação como elemento das redes sociais na Internet e do Fotolog no Brasil como foco de estudo.

\section{Referências Bibliográficas:}

Barabási, A. L. Linked. How everything is connected to everything else and what it means for business, science and everyday life. Cambridge: Plume, 2003.

Bertolini, G. e Bravo, S. (2004) Social Capital, a Multidimensional Concept. Disponível em <http://www.ex.ac.uk/shipss/politics/research/socialcapital/other/bertolini. pdf $>$ Acesso em 17/10/2004.

boyd, d. (2004) Friendster and Publicity Articulated Social Networks. Conference on Human Factores and Computing Systems (CHI 2004), Vienna: ACM, April 24-29, 2004.

boyd, d. (2006) Friends, Friendster and Top 8: Writing Community into Being on Social Network Sites. In First Monday, volume 11, number 12 (December, 
2006). http://www.firstmonday.org/issues/issue11 12/boyd/ Retrieved on January, 2007.

boyd, d. \& Herr, J. (2006) Profiles as Conversation: Network Identity Performance on Friendster. In Proceedings of the Hawai'i International Conference on System Sciences (HICSS-39), Persistent Conversation Track. Kauai, HI: IEEE Computer Society. January 4-7, 2006.

Carvalho, R. M. (2003) Diários Íntimos na Era Digital. Diários Públicos, Mundos Privados. Dissertação de mestrado. Universidade Federal da Bahia, 2003. Disponível em: <http://www.bocc.ubi.pt/pag/oliveira-rosameire-diarios-publicos-mundos-privados.pdf $>$.

Coleman, J. S. (1988) Social Capital and the Creation of Human Capital. American Journal of Sociology, n. 94, p. S95-S120, 1988.

Degenne, A.; e Forsé, M. (1999) Introducing social networks. London: Sage, 1999.

Donath, J. S. (1999) Identity and Deception in the Virtual Community. In: KOLLOCK Peter. e Marc Smith. (organizadores) Communities in Cyberspace. New York: Routledge, 1999.

Döring, N. (2002) Personal Home Pages on the Web: A Review of Research. In: Journal of Computer Mediated Communication, JCMC 7 (3), Abril de 2002. Disponível em <http://jcmc.indiana.edu/vol7/issue3/doering.html>. Acesso em maio de 2007.

Efimova, L. (2005) What is "beneath your current Threshold"? Social Visibility in Persistent Conversations". In Persistent Conversations Workshop, HICSS TUTORIAL DAY, January, 2005.

Ess, C.; Sudweeks, F. ; Hrachovec, H. ; Fragoso, S. (2006) WTF a Crazy Brazilian Invasion. In: CATaC - Cultural Attitudes Towards Technology and Communication, 2006, Tartu. Fifth International Conference on Cultural Attitudes Towards Technology and Communication 2006. Murdoch Australia: School of Information Technology - Murdoch University, 2006. v. 1. p. 255-274.

Granovetter, M. (1973) The Strenght of Weak Ties. The American Journal of Sociology, vol. 78, n. 6, p. 1360-1380, 1973.

Gyarmati, D. e Kyte, D. (2004) Social Capital, Network Formation and the Community Employment Innovation Project. In: Policy Research Iniciative, Volume 6, Number 3. Disponível em

$<$ http://policyresearch.gc.ca/page.asp?pagenm=v6n3_art_05>. Acesso em 04/05/2004.

Lento, T. et al. (2006)The Ties that Blog: Examining the Relationship between social ties and continued participation in the Wallop Weblogging System. Presented at $3^{\text {rd }}$ Annual Workshop on the Weblogging Ecosystem: Agregation, Analysis and Dynamics. The 15th International World Wide Web Conference (WWW 2006). http://www.blogpulse.com/www2006-workshop/papers/Lento-Welser-GuSmith-TiesThatBlog.pdf Retrieved on October, 2006. 
Liu, H., Maes, P. and Davenport, G. (2006) Unraveling the Taste Fabric of Social Network. In International Journal on Semantic Web and Information Systems 2(1), pp. 42 - 71, Hershey, PA: Idea Academic Publishers.

McDonald, D. (2006) Visual Conversation Styles in Web Communities. In Proceedings of the Hawai'i International Conference on System Sciences (HICSS-39), Persistent Conversation Track. Kauai, HI: IEEE Computer Society. January 4-7, 2006.

Mishne, G. and Glance, N. (2006). Leave a Reply: An Analysis of Weblog Comments. Presented at $3^{\text {rd }}$ Annual Workshop on the Weblogging Ecosystem: Agregation, Analysis and Dynamics. In The 15th International World Wide Web Conference (WWW 2006).

Primo, A. (2003) Interação Mediada por Computador: A comunicação e a educação a distância segundo uma perspectiva sistêmico-relacional. Tese de Doutorado. Apresentada ao Programa de Pós-Graduação em Informática na Educação em março de 2003.

Quan-Haase, A. e Wellman, B. (2002) How does the Internet Affect Social Capital. In: HUYSMAN, Marleen e WULF, Volker (org.) IT and Social Capital. Novembro de 2002.

Recuero, R. (2002) Comunidades Virtuais no IRC: o caso do \#Pelotas. Um estudo sobre a Comunicação Mediada por Computador e a estruturação de comunidades virtuais. (Master dissertation) Universidade Federal do Rio Grande do Sul. (janeiro de 2002).

Recuero, R. (2005) O Capital Social em Redes Sociais na Internet. Revista FAMECOS, Porto Alegre, v. 28, n. dez 2005, p. 1-15, 2005.

Recuero, R. (2006) Dinâmicas de Redes Sociais no Orkut e Capital Social. Trabalho apresentado no GT de Internet Comunicación e Sociabilidad do ALAIC, em julho de 2006, São Leopoldo/RS.

Sibilia, P. (2003) Os diários íntimos na internet e a crise da interioridade psicológica. XI encontro da Compós, 2003. Disponível em $<$ http://www.facom.ufba.br/ciberpesquisa/tics/2003/body sibilia 2003.ht $\underline{\mathrm{m}}>$.

Scott, J. (2000) Social network analysis. A handbook. $2^{\text {nd }}$ ed. London, UK: Sage Publications, 2000.

Stutzman, F. (2006) An Evaluation of Identity-sharing Behavior in Social Network Communities. Proceedings of the 2006 iDMAa and IMS Code Conference, Oxford, Ohio.

Towle, J. (2004) Measuring and Evaluating the Underlying Social Networks of Visual Blog Communities. Proceedings of the ACM Conference on Computer Supported Cooperative Work (CSCW), Chicago, Illinois, November 6-10, 2004.

Wasserman, S. e Faust, K. Social network analysis. Methods and applications. Cambridge, UK: Cambridge University Press, 1994. 
Wellman, B. (1997) An Electronic Group is Virtually a Social Network. In: KIESLER, S. (org.) Culture of Internet. (p. 179-205) Hilsdale, NJ: Lawrence Erlbaum, 1997.

Watts, D. (2003) Six Degrees. The Science of a Connected Age. New York: W. W. Norton \&Company, 2003.

Watts, D. J. e Strogatz, S. H. (1998) Collective Dynamics of 'smal-world' networks. In: Revista Nature, vol. 393, p. 440-442, 4 junho de 1998. 